\title{
PENGARUH KOMPOSISI BAHAN PENGISI KAOLIN DAN KARBON HITAM TERHADAP SIFAT FISIK, KEKUATAN TARIK DAN KETAHANAN USANG PADA VULKANISAT KARET ALAM
}

\section{THE EFFECT OF FILLER COMPOSITION OF KAOLIN AND CARBON BLACK TOWARDS ITS PHYSICAL, TENSILE PROPERTIES AND AGEING RESISTANCE OF NATURAL RUBBER VULCANIZATES}

\author{
Tri Susanto* dan Rahmaniar \\ *main contributor and corresponding author \\ Balai Riset dan Standardisasi Industri Palembang \\ JI. Perindustrian II No. 12 Sukarami, Palembang, Sumatera Selatan, Indonesia 30152 \\ e-mail : trisusanto87@gmail.com dan rahmaniar_een@yahoo.co.id.
}

Diterima : 17 Februari 2020; Direvisi : 31 Mei 2020 - 08 Juni 2020; Disetujui : 17 Juni 2020

\begin{abstract}
Abstrak
Karbon hitam merupakan bahan pengisi penguat komersial industri dengan harga yang relatif tinggi yang sering digunakan dalam pembuatan barang karet. Sementara kaolin sangat berpotensi dari sisi sifat fisik, ketersediaan dan harga untuk dijadikan bahan pengisi pendamping dalam pembuatan barang karet alam. Penelitian ini bertujuan untuk mempelajari pengaruh komposisi karbon hitam dan kaolin terhadap sifat fisik, tarik, dan ketahanan usang vulkanisat karet Alam. Kombinasi karbon hitam: kaolin dalam penelitian ini yaitu 50:20; 40:30; 30:40; dan 20:40 phr, dilakukan sesuai dengan proses pembuatan vulkanisat karet alam ASTM D3182. Hasil penelitian menunjukan bahwa dominasi kaolin terhadap karbon hitam memperngaruhi perubahan kekerasan, kuat tarik, dan perpanjangan putusnya. Perbandingan komposisi karbon hitam dan kaolin tidak memberikan efek terhadap ketahanan usang vulkanisat karet alam. Hasil spektra FTIR menambahkan informasi dispersi karbon hitam dan kaolin pada matriks karet alam perlu ditingkatkan.
\end{abstract}

Kata kunci : vulkanisat karet alam, kaolin, karbon hitam, ketahanan usang.

\begin{abstract}
Carbon black is a commercial industrial reinforcement filler with a relatively high price for rubber goods production. In terms of physical properties and availability, kaolin has potential to be used as reinforcing fillers for natural rubber vulcanizates. This study aims to study the effect of the composition of carbon black and kaolin on the physical, tensile, and ageing resistance of natural rubber vulcanisates. The combination of carbon black: kaolin in this study is 50:20; 40:30; 30:40; and 20:40 phr,. Rubber compounding was conducted in accordance with ASTM D3182. The results showed that the dominance of kaolin over black carbon affects changes in hardness, tensile strength, and elongation at break. The composition of carbon black and kaolin does not have an effect on the ageing resistance of natural rubber vulcanizates. FTIR spectra results confirm that the dispersion of carbon black and kaolin in the natural rubber matrix needs to be improved.
\end{abstract}

Keywords: natural rubber vulcanizates, kaolin, carbon black, ageing resistance.

\section{PENDAHULUAN}

Untuk memperbaiki sifat fisik, mekanik dan tarik ulur suatu produk karet, bahan pengisi ditambahkan dalam jumlah tertentu. Spesifikasi teknis bahan pengisi meliputi ukuran partikel, karakteristik permukaan bahan pengisi, tingkat polaritas bahan pengisi, dan efek penguatan pada matriks polimer sangat menentukan kualitas barang karet yang dihasilkan (Arroyo, Lopez-Manchado, \& Herrero, 2003; Zhang, Wang, Lin, \& Mi, 2006). Saat ini, karbon hitam adalah bahan pengisi berbasis minyak bumi yang dominan digunakan pada produk barang karet berwarna hitam misalkan ban, gasket, belt conveyor, engine mounting, rail pad, galangan kapal dan sebagainya (Bondan, 2019; Mohanty, Bhandari, Chandra, Chattopadhyay, \& Chattopadhyay, 2013; Qu et al., 2010). 
Permukaan karbon hitam bersifat nonpolar yang biasanya cocok untuk jenis polimer non polar seperti karet alam (Barrera \& Cornish, 2016). Beberapa isu penting terkait dengan karbon hitam adalah kelangkaan karbon hitam, efek proses produksi karbon hitam yang tidak ramah lingkungan dan harga yang cukup tinggi dibandingkan dengan bahan pengisi lainnya (Zhang et al., 2006). Dalam hal upanya penurunan biaya produksi barang karet tanpa mengubah sifatnya misal kekerasan, berat jenis, kuat tariknya, maka dalam penelitian ini akan dipelajari pencampuran bahan pengisi karbon hitam dengan bahan pengisi mineral lain.

Mengingat kebutuhan jumlah bahan pengisi penguat pada industri produk karet sangat tinggi, berbagai penelitian dikembangkan untuk mempelajari bahan pengisi mineral alam yang melimpah. Berdasarkan karakteristik warna, kebutuhan bahan pengisi putih cukup tinggi dikarenakan sebagai dasar pewarnaan produk karet. Saat ini bahan pengisi warna putih yang komersial adalah precipitated silica, Magnesium carbonat, Barit, Kalsium karbonat, talc, mika dan beberapa mineral lain (Al-Mosawi, Ali, \& Mohmmed, 2012; Arroyo et al., 2003; Raji, Ramakrishnan, Sukumar, Brahmakumar, \& Menon, 2015). Dalam efek penguatannya kaolin dan silika presipitat mempunyai keunggulan penguatan sifat mekanik fisik maupun tarik ulurnya dibandingkan kalsium karbonat ataupun talc. Dalam penelitian ini akan dipelajari kaolin sebagai bahan pengisi penguat campuran karbon hitam pada campuran karet alam.

Kaolin adalah lempung material dengan kandungan rendah besi yang berwarna putih dan agak keputihan. Komposisinya terdiri dari sebagian besar Aluminium Silikat Hidrat dan disertai beberapa mineral pengotor besi oksida, kuarsa dan lain lain (Vijay, Anitha, \& Menon, 2016). Permukaan kaolin lebih polar apabila dibandingkan dengan karbon hitam yang selama ini digunakan. Selain itu kaolin dalam bentuk terhidrasi juga menyebabkan dispersi dan tingkat pencampurannya yang rendah pada permukaan polimer karet alam (Sreelekshmi, Brahmakumar, Sudha, \& Menon, 2017; Yahaya, Adebowale, \& Menon, 2009). Sehingga untuk mengatasi hal tersebut ditambahkan zat pengabung tertentu sehingga bahan pengisi polar dan lebih terdispersi dan membentuk ikatan silang dengan polimer karet.

Selama ini produksi barang karet alam menggunakan bahan pengisi karbon hita (Zhang et al., 2006), kaolin (Yahaya et al., 2009), zeosil (Sukumar \& Menon, 2008), maupun bahan pengisi mineral alam lainnya (Peter, Sreelekshmi, \& Menon, 2018; Raji et al., 2015; Sreelekshmi et al., 2017). Mengingat terbatasnya penelitian tentang pengaruh campuran filler karbon hitam dan kaolin bersama sama pada campuran karet alam, maka penelitian ini menjadi penting untuk mendapatkan data teknis untuk desain barang karet sesuai dengan spesifikasi teknis yang dipersyaratkan. Penelitian ini bertujuan untuk mempelajari pengaruh komposisi karbon hitam dan kaolin terhadap sifat mekanik, kekuatan tarik vulkanisat, dan efek pengusangannya dan pengamatan karakteristik interaksi hybrid filler melalui FTIR. Diharapkan penelitian ini dapat berkontribusi pada ilmu teknis formulasi dan desain praktik pembuatan barang karet seperti sol alas kaki, ban, gasket dan selang karet yang menggunakan kaolin dan karbon hitam sebagai bahan pengisi.

\section{BAHAN DAN METODE}

\section{Bahan dan Peralatan}

Bahan yang digunakan antara lain karet alam (limbah karet sisa sentrifugasi lateks dari PT. Bumi Rambang Kramajaya), karbon hitam N-330 (PT Renergi Indonesia), Kaolin (Sumi Chemical), Asam Stearat, Cumaron Resin, ZnO, Minyak Parafin, CBS, TMTD, PEG, Blowing Agent dan PVI (Global Chemical, Co. Ltd). Peralatan yang digunakan dalam penelitian ini adalah open mill Shanghai China Trade Mark, timbangan, mesin press hidrolik. 


\section{Metode}

Formulasi vulkanisat karet alam dalam penelitian ini menggunakan 100 phr karet alam, 2 phr minyak parafin, 10 phr bahan pengiat $\mathrm{ZnO}, 2$ phr plasticizer Asam Stearat, 5 phr softener cumaroun resin, 1,9 phr CBS , 0,5 phr accelerator tipe TMTD, 1,5 phr accelerator tipe TMQ, $10 \mathrm{phr}$ agen vulkanisator koloidal sulphur, 2 phr PVI, 0,5 blowing agent dan 1 phr PEG. Jumlah filler yang digunakan adalah $70 \mathrm{phr}$ yang selaras dengan jumlah total bahan pengisi pada pembuatan barang karet sol sepatu (Rahmaniar \& Prasetya, 2019), solid tyre (Bondan, 2019), dan tegel karet (Yuniari, 1994) dan vulkanisat pada umumnya (Susilawati, Roza, Rifki, \& Susanto, 2019). Bahan pengisi yang ditambahkan pada penelitian ini divariasikan komposisi karbon hitam dan kaolin (phr/phr) yaitu 50/20; 40/30; 30:40; dan 20:50. Sehingga didapatkan data pengaruh hybrid filler terhadap karakteristik fisik dan kekuatan tarik vulkanisat karet alam.

Pembuatan vulkanisat karet alam dilakukan sesuai dengan standard ASTM D3182 "Standard Practice for Rubber (Materials, Equipment, and Procedures) for Mixing Standard Compounds and Preparing Standard Vulcanized Sheets" and ASTM D3184-89 "Standard Test Methods for Rubber Evaluation of Natural Rubber". Pembuatan vulkanisat karet alam tersebut dilakukan di laboratorium karet Baristand Industri Palembang pada bulan April - Juni 2019 menggunakan peralatan seperti tersebut diatas. Untuk keperluan pengujian vulkanisat karet yang dihasilkan di vulkanisasi pada suhu $140{ }^{\circ} \mathrm{C}$ selama 20 menit menggunakan mesin press hidrolik YG220, Shanghai Rubber Machine Worker, China. Untuk mendapatkan data yang akurat prosedur direplikasi 3 kali.

Vulkanisat karet yang dihasilkan diuji kekerasan shore A sesuai dengan ASTM 2240-15 menggunakan Hardnes tester, Germany. Sedangkan tensile properties seperti kuat tarik dan perpanjangan putus diuji sesuai dengan ASTM D412 pada suhu $26^{\circ} \mathrm{C}$ pada kecepatan cross head $500 \mathrm{~mm} /$ menit menggunakan INSTRON UTM Taiwan
Tearing Machine JT-420. Ketahanan pengusangan diuji sesuai dengan ASTM D573-99 pada suhu sirkulasi udara $70^{\circ} \mathrm{C}$ selama 24 jam pada kecepetan uji frame $5 \mathrm{rpm}$. Ageing Chamber yang digunakan Model VAT 60, ASLI China Test Equipment. Ketahanan Pengusangan ditinjau melalui perubahan nilai kekerasan, kuat tarik, dan perpanjangan putus. Pengujian berat jenis vulkanisat dilakukan berdasarkan ASTM D1817-05 (2011). Sedangkan untuk mengetahui adanya profil ikatan silang pada vulkanisat, dilakukan uji FTIR menggunakan alat FTIR jenis Perkin Elmer dan type Frontier.

\section{HASIL DAN PEMBAHASAN}

Tabel 1 menunjukkan berat jenis vulkanisat karet alam, dapat dilihat bahwa ada kecenderungan pengaruh positif jumlah kaolin terhadap kenaikan berat jenis vulkanisat. Hal ini sesuai dengan beberapa penelitian penggunaan kaolin sebagai bahan pengisi (Susanto, 2019; Vijay et al., 2016; Yahaya et al., 2009), berat jenis vulkanisat karet alam dengan penambahan pengisi kaolin sekitar 1,1-1,3 $\mathrm{g} / \mathrm{cm}^{3}$ sesuai dengan jumlah yang ditambahkan. Hal ini juga didukung dengan data bahwa berat jenis kaolin lebih besar dibandingkan dengan karbon hitam. Pada pencampuran keduanya, pengaruh kaolin ternyata lebih dominan terhadap berat jenis vulkanisat karet alam yang dihasilkan. Dari penampakan fisiknya, vulkanisat dengan komposisi kaolin lebih banyak mempunyai tekstur lebih padat dan permukaan yang compact (Peter et al., 2018; Sukumar \& Menon, 2008; Vijay et al., 2016).

Tabel 1. Pengaruh komposisi karbon hitam: kaolin terhadap berat jenis vulkanisat karet alam

\begin{tabular}{|c|c|c|c|c|c|c|}
\hline \multirow[t]{2}{*}{ No } & \multirow[t]{2}{*}{ Parameter } & \multirow[t]{2}{*}{ Satuan } & \multicolumn{4}{|c|}{$\begin{array}{c}\text { Komposisi } \\
\text { Karbon Hitam : Kaolin }\end{array}$} \\
\hline & & & $50: 20$ & $40: 30$ & $30: 40$ & $20: 50$ \\
\hline 1 & Berat jenis & $\mathrm{g} / \mathrm{cm}^{3}$ & 1,265 & 1,275 & 1,279 & 1,294 \\
\hline
\end{tabular}

Kekerasan vulkanisat berkisar pada nilai 80-83 shore A seperti yang 
ditunjukkan pada Gambar 1. Dengan jumlah bahan pengisi total $70 \mathrm{phr}$, nilai kekerasan karet alam ini sesuai dengan beberapa penelitian terdahulu yang menggunakan karbon hitam maupun kaolin seperti (Barrera \& Cornish, 2016; Liu, Li, Wang, \& Zhang, 2011). Dari hasil penelitian ini, belum dapat terlihat jelas bahwasanya semakin besar porsi karbon hitam dari pada kaolin akan menyebabkan semakin kerasnya vulkanisat. Untuk mengetahui lebih lanjutnya perlu dilakukan reological analysis untuk mengetahui processability dari dual hybrid dan juga dilakukan uji struktur morphologi pencampuran karbon hitam dan kaolin pada matriks karet alam. Berdasarkan klasifikasi kekuatan penguatan pengisi karbon hitam dan kaolin yang keduanya adalah bahan pengisi penguat yang cukup reaktif, maka gambar 2 cukup menjadi bukti konfirmasi bahwa pengaruh penguatan terhadap kekerasan vulkanisat. Walaupun berat jenis cenderung naik dengan bertambahnya kaolin, akan tetapi nilai kekerasannya tidak berbeda jauh dikarenakan interaksi ikatan silang maupun dispersi karbon hitam dan kaolin yang cukup berbeda (Liu et al., 2011; Vijay et al., 2016).
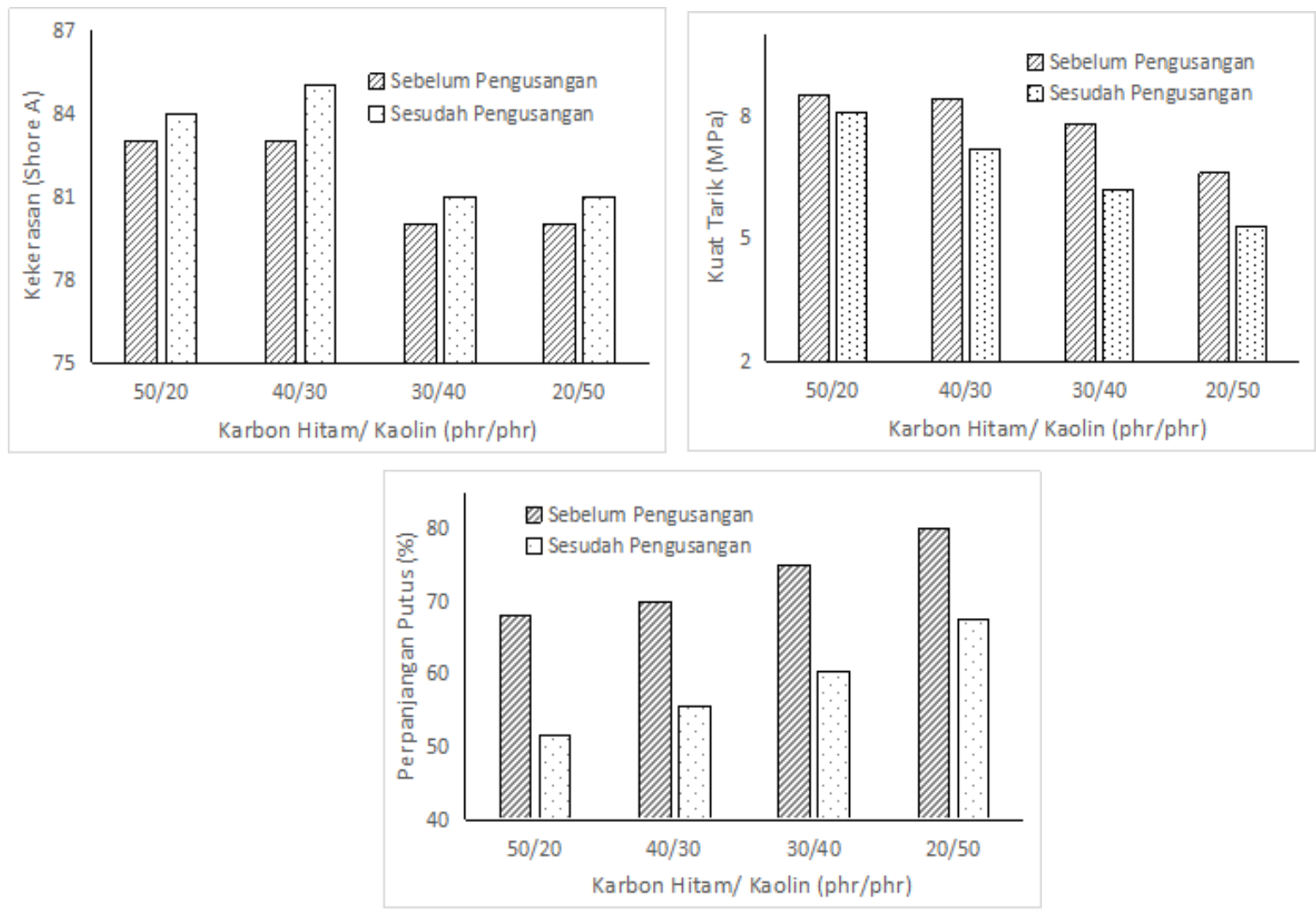

Gambar 1. Pengaruh komposisi karbon hitam/kaolin terhadap kekerasan, kuat tarik, perpanjangan putus dan ketahanan pengusangan.

Kinerja dual bahan pengisi juga mempengaruhi besanya karakteristik tarik ulur seperti kuat tarik vulkanisat karet alam seperti yang digambarkan pada Gambar 2. Dapat terlihat ada kecenderungan penurunan nilai kekuatan tarik vulkanisat dengan bertambahnya porsi kaolin dibandingkan dengan karbon hitam. Hal ini dapat dipahami bahwasanya ukuran partikel kaolin lebih besar dibandingkan dengan karbon hitam sehingga probabilitas dispersi dan processing ability dalam matriks polimer dalam membentuk ikatan silang dengan sulphur akan jauh lebih besar (Rattanasom \& Prasertsri, 2009). Terlebih lagi, polaritas karbon hitam yang hampir mirip dengan karet alam dibandingkan dengan polarnya kaolin dikarenakan adanya gugus silanol 
maupun pengaruh hidrat kaolin akan memperkuat munculnya ikatan hidrogen antara matriks polimer dengan pengisi karbon hitam (Yahaya et al., 2009; Zhang et al., 2006). Tentunya, hal ini akan terjadi berbeda ketika jumlah kaolin mendominasi dalam matriks polimer yang akan menyebabkan melemahnya kuat tarik vulkanisat karet alam. Beberapa penelitian yang menggunakan hybrid filler menemukan hal yang serupa (Liu et al., 2011; Vijay et al., 2016).

Berbeda dengan kecenderungan menurunnya kekuatan tarik vulkanisat, nilai perpanjangan putus cenderung bertambah pada kisaran $68-80 \%$. Nilai perpanjangan putus ini sangat rendah sekali apabila dibandingkan dengan karakteristik karet alam itu sendiri. Beberapa hal yang cukup berpengaruh terhadap nilai perpanjangan putus ini diantaranya jumlah activator yang ditambahkan maupun bahan filler yang digunakan. Total padatan yang ditambahkan dalam vulkanisat selama mastikasi maupun pencampuran dirasakan cukup besar, sehingga memungkinkan adanya aglomerasi maupun distribusi yang tidak rata dikarenakan perbedaan ukuran partikel bahan pengisi kaolin dan karbon hitam. Sehingga interaksi antar muka maupun gaya ikatan akan melemah sehingga nilai kekuatan tarik menurun dan perpanjangan putusnya cenderung turun (Manjhi \& Sarkhel, 2011). Komposisi karbon hitam dan kaolin cenderung menyebabkan perbedaan sifat tarik ulurnya. Hal serupa juga ditemukan pada beberapa penelitan (Barrera \& Cornish, 2016; Manjhi \& Sarkhel, 2011; Mohanty et al., 2013; Vijay et al., 2016). Akan tetapi sedikit berbeda dengan hasil penelitian (Daud, 2015). Hal tersebut bisa dipahami mengingat perbedaan ukuran partikel yang digunakan.
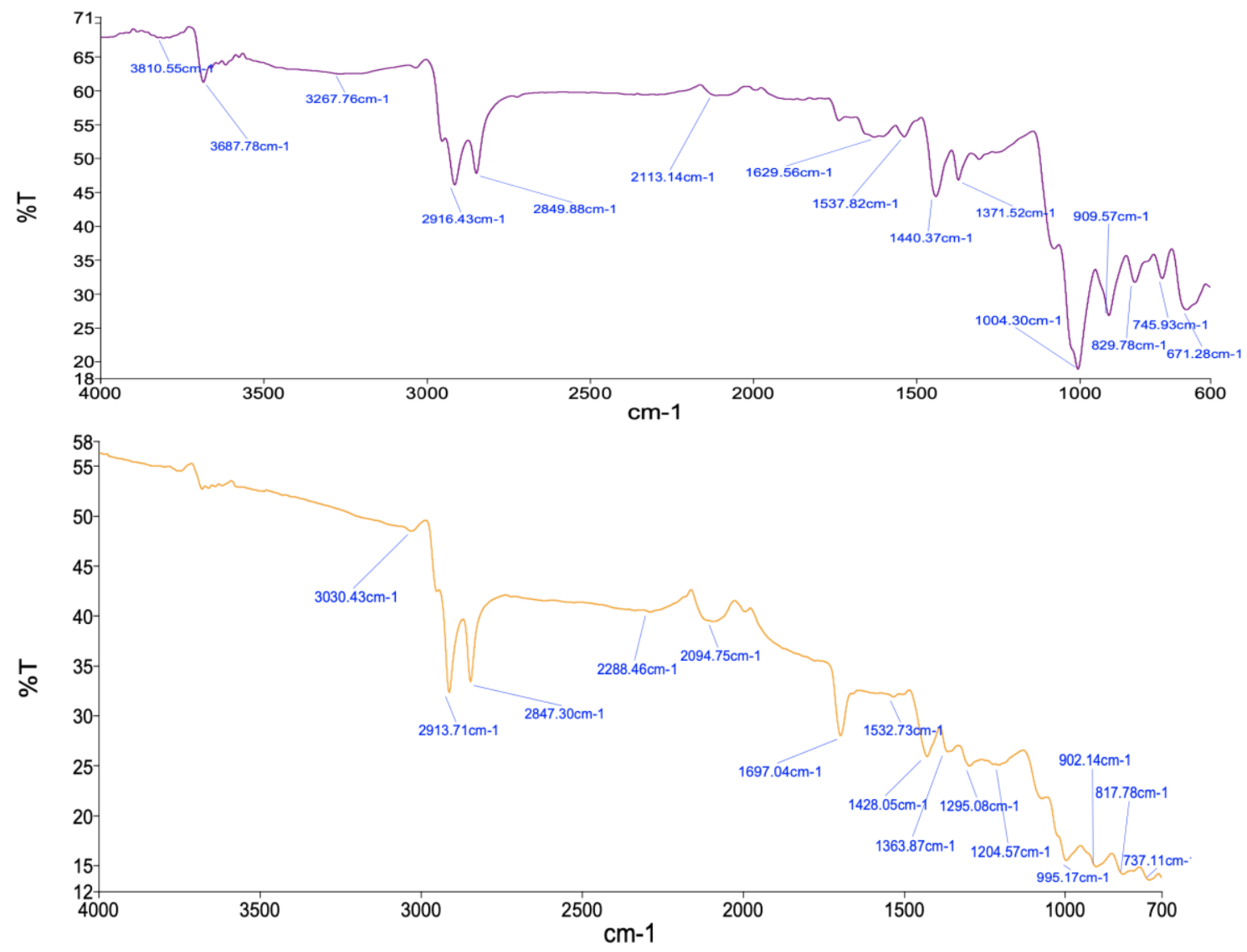

Gambar 2. Spektra FTIR vulkanisat karet alam dengan bahan pengisi karbon hitam: kaolin sebanyak: a. 40:30 phr/phr (Gambar atas); b. 20:50 phr/phr (Gambar bawah). 
Beberapa serapan transmision spektra vulkanisat karet alam ditunjukan pada Gambar 2. Spektra ini mendukung beberapa dugaan adanya pelemahan interaksi dominasi kaolin terhadap karbon hitam pada matriks polimer karet alam yang ditunjukkan dengan melemahnya ikatan $\mathrm{C}=\mathrm{C}$ (isoprene karet alam dan karbon hitam) pada bilangan gelombang 1640an, dan juga gugus fungsi alkana pada karbon hitam C-H pada bilangan 2900 semakin menurun. Sedangkan Adanya kaolin yang cukup mendominasi juga ditunjukkan dengan menguatnya nilai $\mathrm{O}-\mathrm{H}$ pada bilangan gelombang sekitar 3300an dan beberapa gugus lainnya. Hal ini cukup mengkonfirmasi adanya penurunan ikatan silang dikarenakan adanya dominasi kaolin dalam vulkanisat karet alam. Interaksi karbon hitam dan kaolin pada polimer karet alam juga dapat dilihat semakin tingginya peak pada bilangan gelombang 1700an yang kemungkinan interaksi antara gugus hidroksil kaolin, gugus alkana karbon hitam dan gugus alkena isoprene karet alam. Hal serupa juga ditemukan pada penelitian (Arroyo et al., 2003; Rattanasom \& Prasertsri, 2009). Hasil FTIR ini perlu diamati dengan lebih seksama untuk mengkonfirmasi adanya potensi aglomerasi filler maupun lemahnya ikatan pengisi kaolin dan karbon hitam pada karet alam.

\section{KESIMPULAN}

Komposisi kaolin dan karbon hitam cukup berpengaruh terhadap nilai kekerasan, kuat tarik, perpanjangan putus maupun berat jenis vulkanisat karet alam. Dominasi jumlah kaolin terhadap karbon hitam berpengaruh terhadap kenaikan berat jenis dan perpanjangan putusnya. Sedangkan penambahan kaolin berpengaruh negatif terhadap sifat kekerasan dan kekuatan tarik vulkanisat. Adanya aglomerasi, dispersi tidak rata, penurunan ikatan silang akibat perbedaan polaritas kaolin dan karbon hitam menyebabkan penomena tersebut. Dapat dikatakan bahwa komposisi karbon hitam dan kaolin tidak berperan cukup penting dalam hal perubahan nilai pengusangan. Kenaikan nilai kekerasan dan perpanjangan putus serta penurunan kekuatan tarik akibat pengusangan dimungkinkan terjadi akibat loss volatil matter, stifenning effects, dan over vulkanisasi. Hasil spektra FTIR mengkonfirmasi penomena tersebut. Untuk penelitian lebih lanjut, dapat dilakukan uji process-ability, reological analisis, dispersi partikel, maupun profil morfologi campuran kaolin dan karbon hitam dalam polimer karet alam.

\section{UCAPAN TERIMA KASIH}

Kontributor utama dalam karya tulis ilmiah ini menyampaikan terima kasih kepada Dr. Rahmaniar, ST, M.Si atas asistensi dan bimbingannya selama penelitian meliputi validasi data, metodologi dan analisa statistik sehingga karya tulis ilmiah ini dapat diterbitkan. Penulis juga berterimakasih kepada seluruh anggota tim penelitian atas kerjasama dan dukungan dalam penelitian laboratorium maupun pengujian produk karet.

\section{DAFTAR PUSTAKA}

Al-Mosawi, A., Ali, M., \& Mohmmed, J. (2012). Experimental approach to mechanical properties of natural rubber mixing with calcium carbonate powder. International Journal of Physical Sciences, 7(49), 6280-6282.

Arroyo, M., Lopez-Manchado, M., \& Herrero, B. (2003). Organo-montmorillonite as substitute of carbon black in natural rubber compounds. Polymer, 44(8), 2447-2453.

Barrera, C. S., \& Cornish, K. (2016). High performance waste-derived filler/carbon black reinforced guayule natural rubber composites. Industrial Crops and Products, 86, 132-142.

Bondan, A. T. (2019). Natural rubber composites for solid tyre used for forklift tensile properties and morphological characteristics. Paper presented at the Journal of Physics: Conference Series.

Daud, D. (2015). Kaolin sebagai bahan pengisi pada pembuatan kompon 
karet: pengaruh ukuran dan jumlah terhadap sifat mekanik-fisik. Jurnal Dinamika Penelitian Industri, 26(1), 41-48.

Liu, Y., Li, L., Wang, Q., \& Zhang, X. (2011). Fracture properties of natural rubber filled with hybrid carbon black/nanoclay. Journal of polymer research, 18(5), 859-867.

Manjhi, S., \& Sarkhel, G. (2011). Effect of maleic anhydride grafted ethylene propylene diene monomer (MAH-g-EPDM) on the properties of kaolin reinforced EPDM rubber. Journal of applied polymer science, 119(4), 2268-2274.

Mohanty, T. R., Bhandari, V., Chandra, A. K., Chattopadhyay, P. K., \& Chattopadhyay, S. (2013). Role of calcium stearate as a dispersion promoter for new generation carbon black-organoclay based rubber nanocomposites for tyre application. Polymer composites, 34(2), 214-224.

Peter, R., Sreelekshmi, R., \& Menon, A. (2018). Cetyltrimethyl ammonium bromide modified kaolin as a reinforcing filler for natural rubber. Journal of Polymers and the Environment, 26(1), 39-47.

Qu, L., Huang, G., Zhang, P., Nie, Y., Weng, G., \& Wu, J. (2010). Synergistic reinforcement of nanoclay and carbon black in natural rubber. Polymer International, 59(10), 13971402.

Rahmaniar, R., \& Prasetya, H. A. (2019). PENGARUH SUMBER DAYA ALAM LOKAL TERHADAP SIFAT FISIK KOMPON KARET SOL SEPATU KANVAS UNTUK UMUM. Jurnal Dinamika Penelitian Industri, 30(2).

Raji, V. V., Ramakrishnan, S., Sukumar, R., Brahmakumar, M., \& Menon, A. R. (2015). Kaolin modified with sodium salt of rubber seed oil as a reinforcing filler for blends of natural rubber, polybutadiene rubber and acrylonitrile-butadiene rubber. Polymer International, 64(11), 15851593.

Rattanasom, N., \& Prasertsri, S. (2009). Relationship among mechanical properties, heat ageing resistance, cut growth behaviour and morphology in natural rubber: Partial replacement of clay with various types of carbon black at similar hardness level. Polymer Testing, 28(3), 270-276.

Sreelekshmi, R., Brahmakumar, M., Sudha, J., \& Menon, A. R. (2017). Studies on natural rubber containing kaolin modified with hexamethylenediamine derivative of phosphorylated cashew nut shell liquid prepolymer. Applied Clay Science, 141, 171-179.

Sukumar, R., \& Menon, A. (2008). Organomodified kaolin as a reinforcing filler for natural rubber. Journal of applied polymer science, 107(6), 3476-3483.

Susanto, T. (2019). Composites of natural rubber, carbon black, and kaolin sodium bicarbonate content for sponge application. Paper presented at the IOP Conference Series: Materials Science and Engineering.

Susilawati, N., Roza, F., Rifki, R., \& Susanto, T. (2019). Pengaruh Komposit SBR dan Karet Alam dengan Pengisi Karbon Hitam Terhadap Sifat Fisik dan Ketahanan Usang Vulkanisat. Jurnal Dinamika Penelitian Industri, 30(2).

Vijay, V. R., Anitha, A., \& Menon, A. R. (2016). Studies on blends of natural rubber and butadiene rubber containing silica-Organomodified kaolin hybrid filler systems. Polymer, 89, 135-142.

Yahaya, L., Adebowale, K., \& Menon, A. (2009). Mechanical properties of organomodified kaolin/natural rubber vulcanizates. Applied Clay Science, 46(3), 283-288.

Yuniari, A. (1994). Penelitian pembuatan kompon tegel karet dengan menggunakan paraffinic oil pertamina sebagai plasticizer. Majalah Kulit, Karet, dan Plastik, 9(18), 74-79.

Zhang, A., Wang, L., Lin, Y., \& Mi, X. (2006). Carbon black filled powdered natural rubber: Preparation, particle size distribution, mechanical properties, and structures. Journal of applied polymer science, 101(3), 1763-1774. 